\title{
Organ donations from overdose deaths on the rise but stigma remains
}

\author{
- Cite as: CMAJ 2018 June 4;190:E698-9. doi: 10.1503/cmaj.109-5608
}

Posted on cmajnews.com on May 17, 2018.

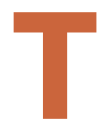
he increase in overdose deaths from the opioid crisis in the United States has led to a sharp rise in the number of organ donations from people who died from overdose. But the stigma surrounding those organs results in many going unused.

Dr. Christine Durand from Johns Hopkins Medical School in Baltimore and her colleagues analyzed all organ transplants in the US listed in the Scientific Registry of Transplant Recipients for the past 17 years. They found a "dramatic rise" in the number of donations from overdosedeath donors. Such donors accounted for only $1.1 \%$ of donations in 2000 , but that increased to $13.4 \%$ by 2017 . "Now more than one in eight deceased donors died from an overdose," she said.

They also looked at how organ recipients fared after receiving donations from overdose deaths compared to other deceased donors and found essentially no difference in standardized five-year survival. "The outcomes were excellent. Equivalent to, if not better than, those from trauma deaths or medical deaths," she said. "We were quite reassured by that."

But organs from overdose deaths, especially kidneys and livers, were also discarded at higher rates than those from other sources. Durand said this is partly because the prevalence of hepatitis $C$ infections was high among those donors, at $30 \%$, which scares off patients and clinicians. But that's not the only reason. "Organs from donors who tested negative are still being discarded," she said.

Most people who died of overdose are designated 'increased infectious risk' donors (IRD), because their lifestyles carried a higher risk of hepatitis and HIV infections. This administrative label has placed an unwarranted stigma on organs from overdose deaths, said Durand. While it is natural for patients to be concerned when they hear that an organ has an increased risk of infection, the tests for disease are so effective that the risk is low for HIV, it is around one in 10000 . For hepatitis $\mathrm{C}$, there is a cure available to treat the recipient if an infection is passed on.

"We could do a better job of educating patients and surgeons [about] what the IRD label means, and put the risk into context," she said. "The risk of dying on the waitlist is much higher."

Dr. Marcelo Cypel, a transplant surgeon at Toronto General Hospital, says surgeons in Canada have also seen a rise in the number of transplant organs from overdose deaths, especially in British Columbia and Ontario, although he did not know exact numbers. Those donors are all considered IRD, but many surgeons and patients are comfortable going ahead with transplants if the donors tested negative for infections. He said other organs that are routinely used - from older donors or smokers, for example - carry higher risks, and the outcomes from overdose-donor transplants are often better because the donors tend to be younger, so their organs are in better condition.

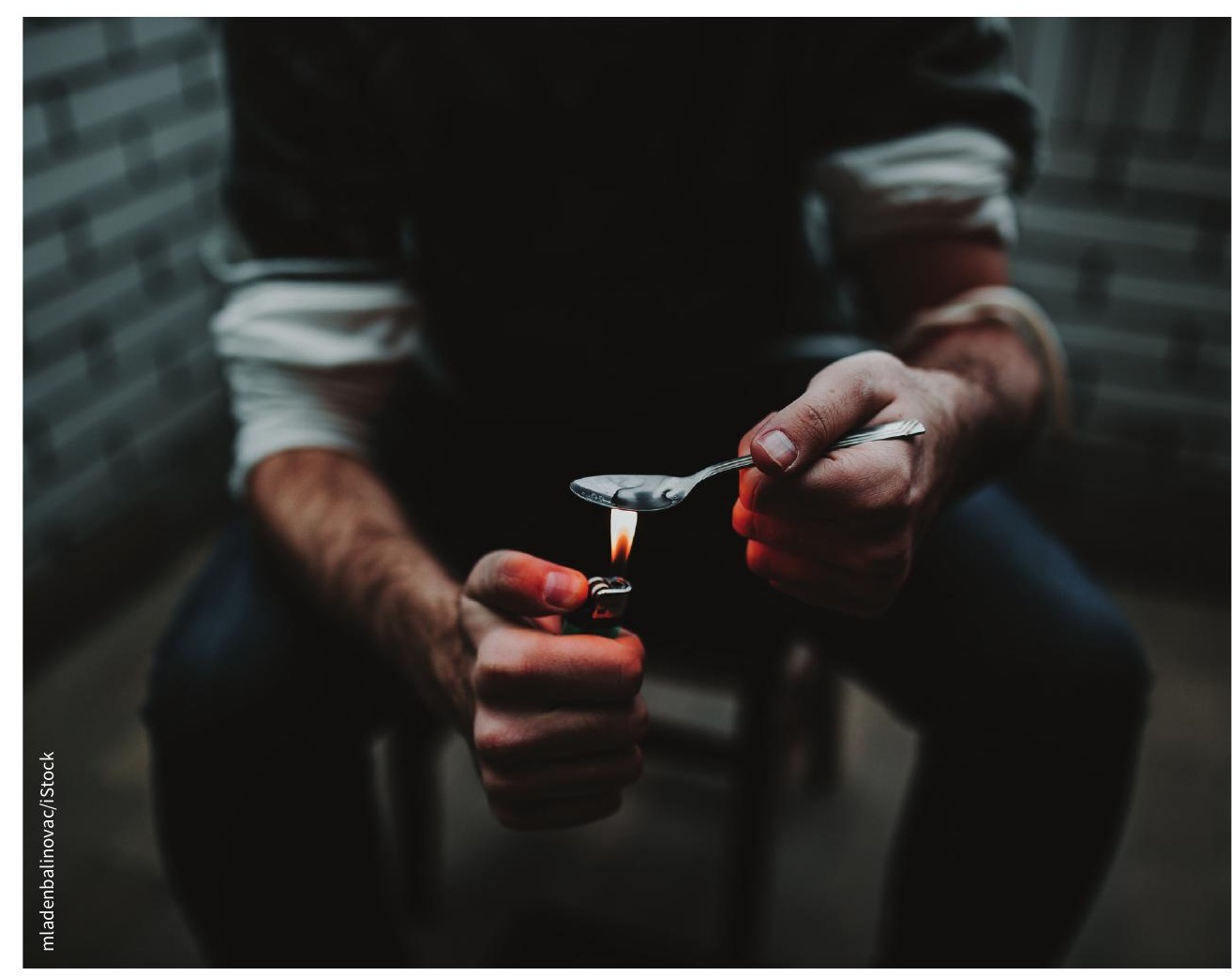

Using more organs from deceased donors who used drugs may help address the transplant organ shortage. 
What surgeons and patients are not yet comfortable with is using organs infected with hepatitis C, but Cypel is working to change that. He is running a trial using infected organs. Patients receive treatment for the disease after surgery. He has done nine successful transplants so far with infected organs.

With a shortage of transplant organs in Canada, it's important not to waste any that become available. James Breckenridge, president of the Canadian Transplant Society, says Canada is among the worse countries in the world for organ donations, with just $20 \%$ of the population registered as donors. "About every other day someone dies without an organ," he said.

Every available organ needs to be considered, regardless of its source, he said. "It's up to the transplant team to decide if an organ is suitable and viable," he said.
"They're not going to use something that will kill the patient."

Durand said it is also important to consider the donors' families, and not throw away an organ just because the donor used drugs. "Donor families are also part of this story," she said. "We have an obligation to use that gift of life and give them some measure of comfort."

Brian Owens, St. Stephens, NB 